\title{
ALGUNOS COMENTARIOS TEÓRICOS SOBRE LA REPRESENTACIÓN EN EL CUENTO "EL CONGRESO" DE JORGE LUIS BORGES
}

\author{
Jorge Aloy \\ Universidad Nacional de Lomas de Zamora (Argentina) \\ jorgealoy@yahoo.com.ar
}

\begin{abstract}
Resumen: Jorge Luis Borges, en el cuento "El congreso" teoriza sobre la representación y, consecuentemente, sugiere la imposibilidad de su realización. En el presente trabajo proponemos efectuar una lectura que exceda el campo de la teoría literaria para, de ese modo, ampliar el horizonte de reflexión en torno al tema. Con ello esperamos alentar un panorama interdisciplinario que se apropie del análisis, ya que este no debe considerarse posesión inherente de la literatura. En ese cruce de perspectivas no creemos que puedan habitar las respuestas a todas las preguntas, pero sí podría hallarse un lugar de encuentro para pensar en común.
\end{abstract}

Palabras clave: sentido, realismo, técnicas, ser-en-común.

\begin{abstract}
In the story "The Congress", Jorge Luis Borges theorizes on representation and, consequently, suggests the impossibility of its realization. The purpose of this work is to do a reading that goes beyond the field of the literary theory, in order to broaden the horizon of reflection around the theme. We hope to encourage an interdisciplinary view which may take ownership of the analysis, since it must not be considered an inherent possession of literature. We do not think that the responses to all the questions may be found in these multiple perspectives, but there might be discovered a meeting point for a common way of thinking.
\end{abstract}

Keywords: sense, realism, techniques, being-in-common.

\section{DOI: $\underline{\text { https://doi.org/10.24029/lejana.2017.10.171 }}$}

Recibido: el 7 de diciembre de 2016

Aceptado: el 31 de enero de 2017

Publicado: el 4 de noviembre de 2017 


\section{Representación, autorrepresentación y antirrepresentación}

En literatura, hablar de representación permite repensar discusiones que se suponían cerradas. Y a pesar de que el siglo XXI muestre sus falencias en cuanto a los fundamentos que la humanidad necesita para su sostén, aún seguimos teorizando; pero ya no para encontrar una base sólida en la ficción que leemos, sino para alimentar las perspectivas filosóficas que puedan relacionar la literatura con otras áreas. Dicho de otro modo: necesitamos ensanchar nuestras perspectivas de reflexión. Por ello, debemos establecer algunas cuestiones, ya que cuando hablamos de representación no estamos muy seguros de que todos hablemos de lo mismo. Claudia Darrigrandi y Felipe Victoriano intentan un esbozo de definición: "[1]a representación, en su sentido más básico, es el resultado de un acto cognitivo por medio del cual se produce un signo o símbolo que se instaura como el «doble» de una presunta «realidad» o de un «original»" (2010: 249). Es decir, que toda representación estaría dada por una suerte de copia de un objeto. En ese caso, podríamos establecer una primera instancia en donde percibimos que la obra literaria remite al mundo en un juego de referencia y referente. Pero también identificamos una segunda instancia en que notamos que la obra remite a la verdad del propio texto. Por lo tanto, si en la primera nos encontramos con la idea de representación, en la segunda surge la idea de autorrepresentación. De esta forma queda al descubierto que el debate literario oscilaba entre el señalamiento de un objeto o la ausencia de todo aquello que fuese externo al texto. Sin embargo, esta dicotomía no se encerró en sí misma y generó una tercera posibilidad: la antirrepresentación. Jean Bessiere señala que

[1]a obra literaria es signo puro, fuera del torniquete de la disposición transitiva y de la disposición intransitiva: actualidad continua de un Yo hablo, sin que haya en ella exposición de esta enunciación. Caen todo doble, todo simulacro, toda autonomía, toda interioridad de la obra. La obra del signo puro parece libre de la mitología que versa sobre la oposición de lo referencial y de lo no referencial, la de una positividad del lenguaje. (2009: 357, los destacados pertenecen a Bessiere)

En concreto, no se presenta un mero juego de oposiciones entre representación y autorrepresentación. O, dicho más claramente, no hay tan solo oposición: la autorrepresentación comparte con la antirrepresentación una puesta en abismo, mientras que la antirrepresentación, además, alude a lo que no puede ser representado. ¿Puede, entonces, una obra literaria, si no toda la literatura, mostrar un fragmento del mundo o ser solo lenguaje sin referencia externa o eclosionar abismalmente en sí misma? Quizá el error de la teorización, planteada como la sistematización de las prácticas literarias, sea el de hacer creer que debemos optar por una opción, y relegar a las restantes. No hay dudas de que si consideramos la posibilidad de la polisemia del texto, debemos considerar, también, que en cada sujeto prevalece una mirada distinta. Y cada una de esas perspectivas fijará una verdad en el texto que se ofrecerá como única, pero que será, a la vez, múltiple. Una explicación, probablemente incompleta, la encontramos en el poder de la letra y las significaciones que irradia. En ese sentido, Roland Barthes nos recuerda que estamos en terreno pantanoso cuando indica: "[1]a escritura está hecha de letras, de acuerdo. Pero, la letra ¿de qué está hecha?" (1986: 107).

Recapitulemos, pues ahora tenemos un sujeto que se dirime en una trifurcación: primero, en donde la representación de la obra literaria se produciría como una remisión al mundo; segundo, en donde la autorrepresentación se convertiría en signo puro y permitiría 
constituir la obra literaria a través de un metalenguaje; y tercero, en donde la antirrepresentación pensaría la obra como una construcción realizada por un lenguaje que contiene al mundo. Probablemente, si decidiéramos en qué lugar pararnos sin que descartemos opciones o, mejor aún, si tomáramos estas tres vertientes como una sumatoria de posibilidades que ayudan a profundizar la reflexión, no habría dudas de que la representación, junto a sus compañeras de viaje, está vinculada a la creación de sentido que produce una obra literaria. Cada una de las opciones cuenta con algún aspecto hiperbólico, pero todas poseen el mismo afán: pensar acerca de la verdad del texto.

En consecuencia, a partir de la tensión que surge entre la relación de la ficción y la realidad, la escuela literaria realista procuró establecer la verdad del texto. Cuando María Teresa Zubiaurre afirma en torno a dicha escuela que "[1]a literatura y el arte han de ser verdaderos y garantizar la fidedigna reproducción del mundo real" (2000: 76), está llamando la atención sobre los propósitos del realismo en cuanto a que debe convertirse en un arte de contemplación y representación de la realidad. Si bien no nos detendremos en ahondar los objetivos del realismo, revisaremos la relación entre escritor y lector, pues en ella se puede percibir el resultado de los efectos propuestos alrededor de lo que esta estética deseaba representar.

La escuela realista, como muchas otras escuelas, prefirió adoptar una postura indiferente sobre lo que los lectores hacían con sus textos. Sin embargo, el efecto del realismo alcanzaba su mayor irradiación en el momento en que intervenía el lector. Esto se producía, precisamente, porque el lector del realismo era un lector propiciado por esta misma escuela cuyo propósito, además de alentar una supuesta transparencia que daría por hecho que aquello leído era exactamente lo vivido, era crear la necesidad de un lector que debía ser sumiso en cuanto a la aceptación de lo que el texto reflejaba. El resultado que se obtenía por esta sumisión era el objetivo que justificaba a toda la escuela literaria. En concreto, lo que se mostraba como una postura indiferente no era otra cosa que el basamento teórico en que se apoyaba la estructura realista. Por ende, cuestionar esta característica constituyente nos introduce en un problema ontológico y abre la posibilidad de hurgar en las aporías que deja el cruce entre lo que el texto dice y lo que el lector hace con ello. En este cruce tendremos que ubicar el cuento "El congreso" de Jorge Luis Borges para pensar la representación.

\section{Ahora, el cuento}

La lectura de ficción reconoce un contrato tácito en donde el lector acepta "un pacto ficcional con el autor, lo que Coleridge llamaba «la suspensión de la incredulidad». El lector tiene que saber que lo que se le cuenta es una historia imaginada, sin por ello pensar que el autor está diciendo una mentira" (Eco, 1996: 85). Por ejemplo, los puntales del pacto ficcional para la estética realista se construían a partir de la omnisciencia narrativa y el ocultamiento de sus procedimientos técnicos. A través de estas herramientas se pretendía alcanzar una escritura fiel y objetiva del mundo, cuyo propósito final sería disolver la distancia entre realidad y ficción. En cambio, el cuento "El congreso" desdeña estos trucos y prefiere realizar el pacto ficcional por medio de otro proceder. Para ello juzga necesario eliminar la omnisciencia narrativa y, en contraposición, incorporar dudas y limitaciones en Alejandro Ferri, el narrador y personaje. 
Ferri, estratégicamente, recurre a la confesión de los hechos. Este recurso no presenta ninguna novedad, pues la confesión juega un papel destacado en el inconsciente de los lectores. En este sentido, Michel Foucault señala que "[a]l menos desde la Edad Media, las sociedades occidentales colocaron la confesión entre los rituales mayores de los cuales se espera la producción de la verdad" (2014: 58). En literatura se busca el efecto o la sensación de verdad, pues el fin último es conseguir que el lector recupere su ingenuidad e inmediatamente se olvide que no cree verdadero lo que lee. Por este motivo, la confesión surge como recurso y debe diferenciarse de la declaración, a pesar de que el narrador presenta determinadas ambigüedades que pretenden plantear un panorama confuso. Ferri no dice que confiesa, sino que declara, y amplifica aún más el desconcierto por el modo en que decide tomar la palabra. La distinción entre declarar y confesar ya la realizó Marcelo Percia cuando indicó que "[s]e declara la guerra, un amor, un derecho, el anhelo de otro mundo. El que declara toma posición, la ofrece, la presta, se hace responsable. Declarar es decidir un lugar, confesar es aceptar que uno estuvo en donde no debió estar" (2006: 81). La confesión de Ferri, si bien está enmascarada, se sitúa en esta lógica, ya que él mismo se considera un perjuro y dice que su declaración es oscura (Borges, 2011: 23). Esto adquiere significación porque él es el único sobreviviente de un acontecimiento denominado El Congreso del Mundo, y todo aquello que narre estará relacionado con la posibilidad de representar el mentado congreso.

El congreso, si bien es el lugar de representación política por antonomasia, en el cuento no se presenta como un espacio físico estable. Incluso no se habla de un lugar, se habla de la representación que, en este caso, alude a la representación del mundo en su sentido más laxo. Por ende, el juego de transposiciones que el mundo debe atender en su camino hacia la concreción de la representación excede lo político e involucra, en el presente relato, lo puramente estético. Sin embargo, en ese juego, el texto no pretende mostrar sus cartas rápidamente, pues Alejandro Ferri plantea un principio técnico: "[d]escreo de los métodos del realismo, género artificial si lo hay; prefiero revelar de una buena vez lo que comprendí gradualmente" (Borges, 2011: 24). En ese momento, la idea de mímesis que el realismo propugnaba quedaría descartada. No obstante, en el mismo momento en que se declama el rechazo a las técnicas del realismo, se aplican recursos que no están muy alejados de esa escuela literaria y que son recurrentes en la obra de Borges. Recordemos que es habitual encontrar en los cuentos del escritor argentino ciertos procedimientos técnicos, tales como señalar que no se falsearán los hechos, utilizar nombres de personas reconocibles, enmarcar la historia en sitios identificables o ceder la autoridad del relato a quien refirió la historia. Alejandro Ferri, en sintonía con las recurrencias borgeanas, comparte diversas características con el propio Borges; por ejemplo, el hecho de que ambos escribieron un ensayo sobre John Wilkins, o que uno llegó a Buenos Aires en 1899 y el otro nació ese mismo año. De todos modos, estos rasgos no convierten el cuento en un género que se sienta propietario de esos recursos, ya que la exageración y la repetición pueden hacer de ello, invariablemente, una parodia.

El modo en que Ferri elige romper con la voz omnisciente es presentarse como un narrador no experto. Con ello pretende alejar toda especulación lectora acerca de sus habilidades técnicas para engañar al lector. $\mathrm{Su}$ desconocimiento pretende invocar cierta transparencia entre el texto y su referencia: "[n]o he acometido nunca, ni siquiera en su 
especie epistolar, el género narrativo y, lo que sin duda es harto más grave, la historia que registraré es increíble" (Borges, 2011: 23). El relato pareciera situarse en un terreno en donde la escasez técnica del narrador permitiría traslucir una historia que es imposible por sí misma, y no a causa de determinados subterfugios utilizados por Ferri. En un reportaje con Fernando Sorrentino, Borges, en referencia a "El congreso", dice que "es un argumento desde luego fantástico - pero no fantástico en el sentido de sobrenatural sino de imposible- porque corresponde a una experiencia mística que yo no he tenido. Yo me propuse referir algo en lo cual yo no creía del todo, a ver cómo me salía" (1996: 74-75). Este comentario del propio Borges nos confirma, tal vez, esta pretensión que percibimos sobre el interés de colocar el argumento en un primer plano. Y el argumento abarca, sin dudas, un repaso acerca de las posibilidades de la representación, de las cuales Borges descreía.

Concretamente, en "El congreso" permanece una tensión entre la representación mimética y una representación que se produciría a través de ciertas semejanzas con el mundo exterior. Mientras que la primera es desdeñada, la segunda no se preocupa por ocultar los hilos de su artificio. Esta distinción se hace evidente en la poca ingenua coincidencia del ensayo que ya mencionamos sobre John Wilkins: Ferri y Borges comparten el estatuto del mundo de la escritura, pero tan solo podemos acceder al ensayo de Borges que, como si ello fuera poco, pone en entredicho la representación. Recordemos que Las palabras y las cosas nació de la risa que le causaba a Michel Foucault (1997) este breve ensayo. En él, Borges cita una enciclopedia china que menciona cómo se clasifican los animales:

a] pertenecientes al Emperador, $b]$ embalsamados, $c$ ] amaestrados, $d]$ lechones, $e]$ sirenas, $f]$ fabulosos, $g$ ] perros sueltos, $h$ ] incluidos en esta clasificación, $i]$ que se agitan como locos, $j]$ innumerables, $k]$ dibujados con un pincel finísimo de pelo de camello, $l]$ etcétera, $\mathrm{m}]$ que acaban de romper el jarrón, $n]$ que de lejos parecen moscas. (1984: 83)

Lo que subyace en el texto es el modo de la representación de las cosas, su arbitrariedad. Discutirlo implicaría discutir la subjetividad. Foucault se pregunta sobre estos animales: “¿en qué lugar podrían encontrarse, a no ser en la voz inmaterial que pronuncia su enumeración, a no ser en la página que la transcribe? ¿Dónde podrían yuxtaponerse a no ser en el no-lugar del lenguaje?" (1997: 2). En tanto, Borges juega con lo absurdo, ya que pone en cuestión el conocimiento, pues las cosas están representadas pero no hallan un punto en común que las hagan inequívocas. En otras palabras, la representación necesita compartir algo común para no exceder sus propias posibilidades. En ese sentido, la relación entre las cosas y el conocimiento no puede establecerse ni como única ni como definitiva, pero tampoco como fugaz o momentánea. Esta inestabilidad es la que pone en entredicho la representación. En "El congreso" nada de esto queda sin explicitar:

[1]as palabras son símbolos que postulan una memoria compartida. La que ahora quiero historiar es mía solamente; quienes la compartieron han muerto. Los místicos invocan una rosa, un beso, un pájaro que es todos los pájaros, un sol que es todas las estrellas y el sol. Un cántaro de vino, un jardín o el acto sexual. De esas metáforas ninguna me sirve para esa larga noche de júbilo, que nos dejó, cansados y felices, en los linderos de la aurora. (Borges, 2011: 32)

La narración del recuerdo que Ferri realiza es de un acontecimiento y una época de los que solo él sobrevive. Que todos hayan muerto no indica nada más que no haya constatación sobre lo que relata, sino, y aún mucho más significativo, enfatiza lo que venimos señalando 
acerca de la necesidad de hallar un punto en común. ¿Es posible pensar la representación desde la idea del ser-en-común, tal como lo sugiere Jean Luc Nancy? El ser-en-común es una condición para atravesar un mundo plagado de individualismos (en plural): "[s]er-juntos no es un conjunto de ser-sujetos, y tampoco es él mismo un sujeto: lo que quiere decir que no vuelve sobre sí mismo, aunque no vaya a otro lugar" (Nancy, 2000: 17). El ser-en-común refiere al encuentro de unos con otros, y también al encuentro entre unos y otros; pero no describe un lugar, ya que ese encuentro es el lugar, es el mundo:

Semejante lugar se denomina sentido. Ser-con es tener sentido, es ser en el sentido o según el sentido, "sentido» que no es en absoluto un vector orientado hacia la epifanía de una significación, sino la circulación de la proximidad en su alejamiento propio, y del alejamiento en su proximidad: la devolución o el rebote de próximo en próximo por el cual un mundo hace un mundo, algo distinto que un montón o un punto nulo. (Nancy, 2000: 17-18)

Si en el cuento de Borges no hallamos posibilidad del ser-en-común, quedaría, inevitablemente, desintegrada la eventualidad de la representación, pero no por la megalomanía del propósito literario de intentar proyectar el mundo en un texto, sino porque en el mismo texto convive la crítica a ese propósito. Ferri $-_{0}$, si preferimos, en este caso podríamos decir Borges- no desconoce que una de las formas de asociación con que contamos para leer ficción es pensar en la semejanza, tal como en la metáfora. De este modo, ya no quedaría espacio para imaginar la representación del mundo sin caer en el reconocimiento de un artificio técnico. En ese sentido, Paul Ricoeur dice que "[1]a metáfora sólo concierne a la sustancia del lenguaje, a las relaciones de sentido" (2001: 242). Entonces, el intento de representación, a través de las diversas técnicas con que cuenta la literatura, parece infructuoso. En definitiva, "El congreso" no pretende representar el mundo; por el contrario, alerta sobre la imposibilidad de lograrlo. Por la tanto, la contienda se inscribe en el plano netamente filosófico: "[p]lanear una asamblea que representara a todos los hombres era como fijar el número exacto de los arquetipos platónicos, enigma que ha atareado durante siglos la perplejidad de los pensadores" (Borges, 2011: 25). Quizá la propuesta deba ser que tenemos que encontrar nuevos modos de leer ficción, ya que muchas veces leemos obras rupturistas desde planos que le son añejos. Pensar desde la filosofía algunas cuestiones teóricas permite encontrar en la ficción algún fragmento de ese mundo del ser-en-común, un fragmento de sentido en un mundo que carece de todo sentido, hablemos del mundo habitado o del mundo representado (si es que ello fuera posible): "[1]a representación es el lugar de la ilusión trascendental”, dice Gilles Deleuze (2002: 394), y no nos deja más opciones que pensar la representación ya no como un artilugio que adopta la literatura, sino como el lugar mismo de la confluencia del ser-en-común que, más allá de surgir como una ilusión, es el lugar de la convivencia. Deleuze afirma que "[e]sta ilusión tiene varias formas, cuatro formas interpenetradas que corresponden particularmente, al pensamiento, a lo sensible, a la Idea y al ser" (2002: 394). Dentro de la complejidad y la profundización que el análisis de estas cuatro formas requiere, tan solo diremos que la representación se hace plausible a través de un acercamiento hacia el presente de aquello a lo que refiere. En otras palabras, la representación es una ilusión en donde el sujeto realiza el inaccesible ejercicio de volver a la presencia aquello que, probablemente, jamás existió.

En "El congreso", finalmente, la imposibilidad de la representación surge porque no hay nada para traer al presente, pues todo está en el presente: “[e]1 Congreso del Mundo 
comenzó con el primer instante del mundo y proseguirá cuando seamos polvo. No hay un lugar en que no esté" (Borges, 2011: 31). El congreso borgeano prescinde de la temporalidad, pero transforma esa ausencia en una perenne presencia de algo que está al alcance y no requiere representación. Por último, y en consecuencia, vuelve a cobrar vida la técnica narrativa, ya que Alejandro Ferri deberá representar aquello que es imposible. Sin embargo, lo imposible se podrá desentrañar tan solo en el ensanchamiento de las perspectivas de análisis.

\section{Bibliografía}

BARTHES, Roland (1986): Lo obvio y lo obtuso. Imágenes, gestos, voces. Barcelona, Paidós Ibérica.

BESSIERE, Jean (2009): "Literatura y representación”. Teoría literaria. Dir. Marc Angenot, Jean Bessiere, Douwe Fokkema y Eva Kushner. México, Siglo XXI: 356-375.

BORGES, Jorge Luis (1984): "El idioma analítico de John Wilkins". Obras completas II. Barcelona, Emecé: 81-84.

--- (2011): “El congreso”. Obras completas III (1975-1985). Buenos Aires, Emecé: 22-33.

DARRIGRANDI, Claudia y Felipe Victoriano (2010): "Representación". Diccionario de estudios culturales latinoamericanos. Coord. Mónica Szurmuk y Robert McKee Irwin. México, Siglo XXI, Instituto Mora: 249-254.

DELEUZE, Gilles (2002): Diferencia y repetición. Buenos Aires, Amorrortu.

ECO, Umberto (1996): Seis paseos por los bosques narrativos. Barcelona, Lumen.

FOUCAULT, Michel (1997): Las palabras y las cosas. Una arqueología de las ciencias humanas. Madrid, Siglo XXI.

--- (2014): Historia de la sexualidad 1. La voluntad del saber. Buenos Aires, Siglo XXI.

NANCY, Jean-Luc (2007): "Conloquium”. Roberto Espósito: Communitas: origen y destino de la comunidad. Buenos Aires, Amorrortu: 9-19. DOI: https://doi.org/10.1215/00265667$\underline{2010-75-101}$

PERCIA, Marcelo: "Modos de alojar un sinfin: literatura, política, psicoanálisis". Pensamiento de los confines 18 (junio 2006): 81-92.

RICOEUR, Paul (2001): La metáfora viva. Madrid, Editorial Trotta, Editorial Cristiandad.

SORRENTINO, Fernando (1996): Siete conversaciones con Borges. Buenos Aires, El Ateneo.

ZUBIAURRE, María Teresa (2000): El espacio en la novela realista. México, Fondo de Cultura Económica.

(C) Jorge Aloy

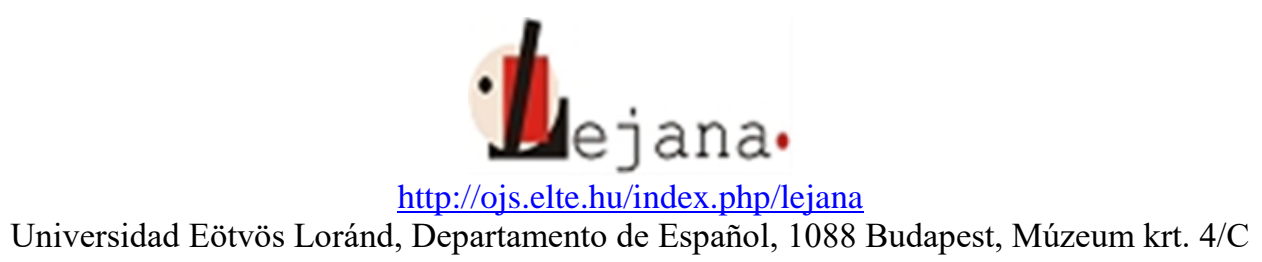

